\title{
1. Introduction. A context-specific two-way approach to the study of innovation systems in developing and transition countries
}

\section{Jana Schmutzler, Marcela Suarez, Alexandra Tsvetkova and Alessandra Faggian}

Innovation is the cornerstone of success in the modern economy at firm, industry, regional, and national levels. An enormous body of academic literature documents how innovation and innovative practices flourish in the fertile environments of mature market economies, driving sustainable economic growth. A young strand of the literature, interdisciplinary in nature, investigates national innovation systems (Lundvall, 1992; Nelson, 1993) and, more recently, innovation systems at the regional (Asheim and Gertler, 2004; Uyarra, 2010), sectoral (Malerba, 2002), technological (Carlsson and Stankiewitz, 1991) and corporate (Granstrand, 2000) levels. This new strand argues that the innovation and learning of a nation or a region reflect the development of specific, systemic arrangements that include firms, institutions, and socioeconomic structures and relationships among them (Lundvall, 1992). Understanding innovative systems is therefore crucial to facilitate and enhance innovation in a more efficient, context-specific way. The significance of such an educated approach, which takes into account local factors and specificities, is especially important in the economic environment of developing and transition countries. Since innovation is a main driver of economic development (Malecki, 1997), it plays a fundamental role in achieving the goal - set by many less developed countries - of closing the economic gap with the developed world.

A study of innovative systems and their elements, however, is remarkably different in developing countries due to the (sometimes) elusive nature of their formal institutions, the prevalence of customs and traditions over laws, and the specific motivations of the agents involved in innovative activities at various levels (Altenburg, 2011). Acknowledging the importance of research on National Innovation Systems (NISs) in developing countries, 
recent scholarship has discussed the applicability of the NIS concept and whether it can serve successfully as an analytical tool and framework for decision-makers designing policy or firm strategies in such countries (e.g. Lundvall et al., 2011). Within this discourse, a specialized body of literature details the evidence on NISs in developing countries (e.g. Arocena and Sutz, 2000b; Cassiolato et al., 2003; Nour, 2016). A broad concept of an NIS which encompasses "relationships within and between organizations, institutions and socio-economic structures" (e.g. Lundvall et al., 2011, p. 6) has been the key for these analyses. However, it is clear that even this broad definition of an NIS is challenged by the realities of developing countries.

Arocena and Sutz (2000b), for example, argued that the NIS in the developing countries of Latin America has an ex-ante character, where micro-economic behaviour, aiming at generating innovation, remains rather isolated and does not integrate in a system-like manner. This may reflect the distinctive characteristics of developing countries with regard to their formal and informal institutions. Other authors have underlined the importance of economic development that is inclusive and proposed the articulation of the Science, Technology and Innovation (STI) policies that account for social needs (Lalics, 2014). As countries have shown increasing rates of economic growth that does not give rise to learning and collaboration processes, which benefit the broader society, the focus is shifting to an inclusive notion of development (Johnson and Andersen, 2012; Dutrénit and Sutz, 2014; Lalics, 2014). In this sense, developing countries face a constant tension between the need to follow a transnational scientific agenda in order to facilitate the technological catch-up process, and the pressing demand to implement local policies aimed at solving urgent social problems. These tensions become ever more important in the face of budgetary restrictions where elementary social needs and the support of innovation processes compete for limited public funding.

Another specific challenge highlighted in this book is the tensions related to the transition processes such as those in post-Soviet contexts (the case of Armenia in Chapter 3) or caused by political turmoil in the Middle East during the recent years (the case of Tunisia's Jasmine Revolution in Chapter 4). These tensions are rendered visible in the coexisting structures of old and new systems, institutions and practices that explain the fragmentation of policies and scarce interactions among actors. Weak institutions, together with the lack of transparency and accountability in policymaking, are fostering economic structures that promote the accumulation of knowledge, infrastructure and capacities in already well-positioned companies. As a result, STI activities are often concentrated in certain regions, sectors and companies (mostly large or multinational firms), which dominate policy agenda-setting. 
In spite of all aforementioned challenges and debates, the study of NISs in developing and transition countries offers both theoretical and methodological opportunities to overcome some of the limitations of current academic debates and to offer a fresh perspective on the role that governments and private actors play in promoting innovative activities in developing and transition countries with a specific focus on policy approaches, collaboration and learning. The chapters in this book explicitly link these issues to cultural inheritance, economic structures and political contexts that are central to understanding innovation processes in this group of nations. By conveying the richness of the different experiences coming from nine developing and transition countries located on four continents, this book provides a detailed view documenting and analysing the diversity of challenges and adaptive strategies taken by firms, industries and governments in the less developed part of the world in order to succeed in global competition.

This book is divided into two parts, following the broad definition of an NIS. A broad perspective on NISs implies that the system level shapes the way competences are built, learning takes place and innovations are generated, while at the same time the interactions at the micro level are reflected in changes taking place at the system level (Lundvall et al., 2011). The first part of the book "The role of public policies in developing and transforming national and sectoral innovation systems" comprises five chapters that address a public policy (system level) perspective on NISs for developing and transition countries. The next five chapters in the second part of the book "Innovation challenges and response strategies in national and sectoral innovation systems: A firm-level perspective" bring in the micro perspective and document interactions both among individual firms and between firms and regional or national actors such as governmental bodies or universities. Taken as a whole, the book offers a balanced and rounded empirical perspective on the two levels of the NIS concept.

As shown by numerous chapters in this book (with Chapters 2-6 offering a more detailed discussion), government actions contribute tremendously to the establishment of innovation capabilities, a point emphasized by the NIS literature. However, state intervention per se is only a part of the picture. Within the broad NIS definition, the macro level is linked to the micro behaviour in a two-way manner (Lundvall et al., 2011). Changes at the macro level induced by the government should be aimed towards shaping the learning and competence-building processes at the micro level within firms, universities and the like, while at the same time public policies should reflect the feedback received from the micro level. Chapters 2-6 provide ample material for discussion especially on the latter point.

In most general terms, Chapters 2 through 6 present a discussion of 
whether the NIS framework can serve as an analytical and/or a normative tool in these contexts. All chapters recognize the need to adopt a broad NIS definition (Lundvall et al., 2011). In other words, an explicit focus on sociocultural institutions, macroeconomic conditions and various infrastructures that potentially impact learning and competence-building processes, as well as interactions among different actors at various levels, appears crucial for a deeper understanding of actual and potential challenges faced by NISs in these countries. Such a deeper understanding enables scholars to advance research and, most importantly, may offer insights necessary for policymakers and practitioners to design policies aimed at the development and consolidation of NISs. As such, the analyses presented in the book chapters make a strong point in favour of context-dependent NIS development that builds on and takes advantage of the uniqueness of local milieu.

Additionally, the book stresses the importance of the often-overlooked informal institutions. Informal institutions are not necessarily made explicit or even communicated among social actors and they are - unlike formal institutions - self-enforcing. Informal institutions include conventions, codes of conduct, norms and moral values, which constrain the behaviour and actions of economic actors (North, 1990). With informal institutions being difficult to measure, research (including the research focused on the NIS concept) has been strongly biased towards formal institutions. Drawing on in-depth case studies, the first part of this book is able to show that informal institutions matter in the context of developing and transition countries where formal institutions are weak and underdeveloped. It appears that informal elements such as trust among various economic actors within an NIS directly interact with public policies in determining the success of an NIS.

Chapter 2, by Miklos Lukacs de Pereny, analyses Peru's public policies in the transition from industrialization to innovation-based development during the 1968-2015 period. The author provides a detailed overview of the Peruvian NIS-building throughout this period. More importantly, the chapter relates this transformation to economic, political and institutional changes, pointing out barriers, which have limited the success of the Peruvian NIS. This historical analysis enables the reader not only to scrutinize the influence of sociocultural and economic structures on the NIS formation, but also to observe path dependencies in the development of public policies within Peruvian NISs, which have been significant. The author highlights coordination problems among economic actors within the NIS and stresses the importance of the NIS's informal dimensions, such as willingness to cooperate or a lack of trust in state agents by Peruvian firms. 
In a similar vein, Tatevik Poghosyan in Chapter 3 analyses the Armenian NIS, highlighting the country's experiences in the transition from a socialist system to a market economy. The chapter shows that, even though Armenia was a highly industrialized country, the "Soviet culture", understood as the historical heritage, technological specialization and prevailing innovation practices, has shaped the challenges faced by the country in its innovation-led development and the barriers that still hinder economic growth. The chapter demonstrates that a broad definition of an NIS coupled with the analysis of socio-economic and cultural traditions contributes to understanding of current economic processes in Armenia. Since the Soviet legacy is very unique, the chapter is able to validate another important point that many chapters in this book make, that is, the influence of the past is very persistent and may last many decades. For policymakers this points to the fact that the real change is likely to be slow, whereas short-term measures that are not ingrained in local culture are unlikely to have lasting effects.

Chapter 3 and Chapter 4 are a testimony to the importance of the sociopolitical environment in determining the way Innovation Systems (IS) are structured, built and how they evolve. In Chapter 4, Nejla Yacoub describes the Tunisia's pharmaceutical innovation system before the Jasmine Revolution and explores to what extent a more democratic environment, brought about by the revolution, enhances learning and competence-building in the context of a sectoral innovation system (SIS). Based on a detailed description and analysis of the macro environment, combined with a survey of pharmaceutical companies, the author shows the threats and opportunities presented to the pharmaceutical industry by the Jasmine Revolution in Tunisia. In contrast to the previous chapter, the eventual effect of the political turnaround on the SIS development is yet to be seen. A close comparison of the NIS in transition countries such as that described in Chapter 3 might be useful in understanding the possible trajectories of development, post-revolution. Such comparisons, though appropriate and requested (Lundvall et al., 2011), should be undertaken with education purposes rather than as a basis for specific policy approaches. This book shows that the sociocultural contexts of transition countries in Europe and of some Arabic countries, which tried to incorporate democratic elements in their political systems, differ considerably. Based on the observation that the evolution of an NIS is path-dependent, shaped by history and institutional composition, public policies successful in one context may not necessarily lead to the same result elsewhere.

The next chapter (Chapter 5) by Cecilia Tomassini Urti tackles a different but extremely important question of social impacts of technology-led 
economic growth. Even when considerable resources are allocated to support the key NIS actors and to promote competence-building, society as a whole may not necessarily benefit. In fact, advanced technological development often leads to negative distributional consequences (Altenburg, 2011). For developing - and to a lesser extent transition countries this issue is of utmost importance given their prevalent high levels of poverty. It is a common practice that the STI policies and the Millennium Development Goals ${ }^{1}$-based policies are competing for limited public resources. As a result, the concept of inclusive innovation has received increasing attention. The idea of inclusive innovation is based on an assumption that innovation/technology and social policies can and should be developed in such a way as to promote the same outcomes reinforcing the impacts on each other (Paunov, 2013). The case of the Brazilian healthcare sector, analysed by Cecilia Tomassini Urti in Chapter 5, shows that the allocation of resources and the generation of capacities linked to NISs are not enough. Through document analysis and semi-structured interviews with policymakers and healthcare scholars, the author details the trajectory of public policies that support science, technology and innovation in this industrial sector. In particular, the analysis shows how the promotion of healthcare - as an example of a social inclusion goal to be attained - has been incorporated into STI policies. Whereas Chapter 2 provides evidence for the need to integrate the micro and the macro levels within an NIS, Chapter 5 draws attention to another important requirement for a harmonious and successful NIS development, the synchronization of the end policy targets and of policy actors' actions across all governmental bodies and programmes. When the traditional aim of an NIS to generate competence-building and learning as a means to promote innovation and to stimulate economic growth is supplemented with the aim to generate social inclusion, a mix of effective policy instruments has to be expanded to centrally include mechanisms of policy coordination, such as political agreements, national conferences, public and private partnerships in addition to special programmes that articulate specific roles of policy actors involved in the process.

Hernán Alejandro Morero in Chapter 6 provides further evidence on the importance of coordination between the different actors and levels of an NIS. Through a case study of the software industry in Argentina, this chapter provides empirical evidence for complementarities between the use of internal and external innovation sources for firms' innovative activities in this sector. Unlike other empirical studies that evaluate whether internal and external innovation sources have complementarity or substitution effects, the author emphasizes the role public policies play in encouraging software companies to invest in innovations internally in addition to 
collaborating externally for the innovation process. As such, this chapter contributes to the discussion of the role the system level plays in shaping the behaviour of economic actors at the micro level.

With this, Chapter 6 builds a bridge to the second part of the book. Lundvall and colleagues argued that within the broad definition of an NIS, "learning will reflect the prevailing institutions and the socio-economic structure" (Lundvall et al., 2011 p.6). After a public policy perspective adopted by the chapters in the first part of the book, the second part evaluates challenges to national and sectoral innovation systems and presents strategies to overcome these challenges from the perspective of a firm. The contributions in the second part of the book link the firm-level learning and collaboration strategies to the context-dependent systemic level.

In Chapter 7, Gulifeiya Abuduxike and Syed Mohamed Aljunid identify the main challenges that the Malaysian firms face in the health biotechnology knowledge field and suggest potential strategies, which according to the private firms in this sectoral innovation system should be implemented. Through a mixed-method approach that consists of semi-structured interviews, a survey and focus groups combined with secondary data triangulation, the authors nicely complement the discussion of Chapters 2 through 5, showing that a lack of trust among economic actors in this sector hampers cooperation and coordination not only among firms but also among governmental institutions, leading to uncoordinated, and thus ineffective, sectoral innovation system public policies.

The following chapters (Chapters 8-11) focus on the challenge of enabling sustainable interactions, cooperation and coordination. While collaboration strategies driving the processes of competence-building and learning are a central component of any NIS, much of the current research, including most of the chapters contained in this volume, shows a lack of strong linkages between various actors within an NIS. Parting from the underlying premise that innovation is an interactive process (Lundvall, 1992), the concept of an NIS is relational (Arocena and Sutz, 2000a). A close interaction and connection between various actors within an NIS is key, especially in less developed parts of the world (Arocena and Sutz, 2000a). At the same time, formal and informal collaborations are a central aspect of firms' innovation strategies (Srholec and Verspagen, 2008). In the context of developing and transition countries, it is argued that firms rely on collaborations as an essential tool for overcoming the numerous barriers they face (McCormick and Atieno, 2002), including underdeveloped, highly volatile and unreliable formal institutions as well as small, fragmented and imperfect markets. Another distinguishing 
feature of developing countries is a weak coordination between actors comprising an NIS coupled with infrequent collaborations at the firm level (Arocena and Sutz, 2000a; de Melo et al., 2001).

The potential for learning opportunities, which have opened up in the new global landscape - characterized by economic globalization, new business strategies and the enabling technological developments is large (Archibugi and Pietrobelli, 2003). Some developing countries were particularly successful in exploiting these opportunities via active collaboration and networking. However, many other countries have failed to benefit from collaboration and learning (Chaminade and Vang, 2008). Thus, a deeper understanding of how firms in developing and transition countries may successfully tap into information flows, through collaboration in general and through collaboration with international economic partners in particular, is important. Chapters 8 and 9 explore the link between the collaboration and networking strategies of firms and their innovation processes. Oluseye Oladayo Jegede in Chapter 8 focuses on collaboration strategies of firms in the Nigerian mining sector. Through questionnaires, structured interviews, and field observations of 150 mining companies, the author shows the impact that these strategies had on the process of innovation. Despite a very different socio-economic context, Chapter 8 accounts, just as Chapters 2 and 3, for similar barriers for the consolidation of the IS: weak interactions between private firms and public or governmental institutions. In Chapter 9, László Csonka presents comparable evidence from a survey of Hungarian small and medium enterprises (SMEs), offering insights into the motivation to collaborate both domestically and internationally, together with other important factors that shape collaboration and networking strategies of SMEs in this transition country.

Extending the discussion on interactions among various actors of an NIS, Carlos Gonzalo Acevedo Peña, Walter Mauricio Hernán Céspedes Quiroga and José Eduardo Zambrana Montán discuss in Chapter 10 the role of public Bolivian university Universidad Mayor de San Simón in promoting an innovation system by acting as a bridgebuilder. Through a participatory research at the university's technology transfer office, the authors contend that at least two factors are at the core of competence-building and learning processes. In addition to the central role played by social relations among NIS participants, the alignment of goals among participating actors is equally or even more important. Only when each actor involved comprehends the necessities and capabilities of the other, may effective coordination and cooperation take place. As a result, the authors highlight how the concept of a developmental university exemplifies a new societal role that a university 
can play in developing countries contributing to a range of desirable social and economic ends.

In the last chapter (Chapter 11), Xiao-Shan Yap and Rajah Rasiah evaluate collaboration from a very different angle. Based on four case studies in the Malaysian wafer fabrication and semiconductor sector, the authors document how indigenous firms employ learning strategies to catch up by incorporating into global value chains (GVC). The inflow of knowledge and technology from foreign sources has long been considered crucial for developing countries' catching-up process, and participation in GVC may be an effective way to achieve this goal (Pietrobelli and Rabellotti, 2011). The chapter expands our knowledge on the determinants of successful participation in GVC by developing a taxonomy of latecomer business strategies that relates strategic choices to their promise for success.

It has been our aim to provide evidence for the applicability of the NIS concept (perhaps with some adjustments) in developing and transition countries through this book. The chapters of this volume demonstrate that a broad definition supplemented by the explicit focus on the influence of the sociocultural context, macroeconomic structures and institutions is the only way to ensure a deep understanding of innovation processes in these contexts. At the same time, it is the systemic element of this definition that the various chapters of this handbook provide plentiful evidence for. Taken as a whole, the book shows how the system level influences the way firms and other actors build up competences and learn, while demonstrating that the outcomes of interactions among actors at the micro level shape the NIS environment. It is crucial for the governments to account for this environment when devising innovation-focused strategies and approaches. We have attempted to provide detailed descriptions and analyses of some specific challenges faced by policymakers, firms and other economic actors who are engaged in the development and consolidation of an NIS. We believe that the book offers abundant material for learning and further discussions to both students of the NIS and practitioners working to build successful and efficient Innovation Systems in their countries and hope it will be instrumental in promoting engaged and well-informed dialogue on the issue.

\section{NOTE}

1. Millennium Development Goals were defined by the United Nations with the target date 2015 (http://www.un.org/millenniumgoals/). 


\section{REFERENCES}

Altenburg, T. (2011). Building inclusive innovation systems in developing countries: Challenges for IS research. In B.-Å. Lundvall, K. Joseph, C. Chaminade and J. Vang (eds.), Handbook of innovation systems and developing countries: Building domestic capabilities in a global setting (pp. 33-56). Cheltenham, UK and Northhampton, MA: Edward Elgar Publishing.

Archibugi, D., and Pietrobelli, C. (2003). The globalisation of technology and its implications for developing countries: Windows of opportunity or further burden? Technological Forecasting and Social Change, 70(9), 861-883.

Arocena, R., and Sutz, J. (2000a). Looking at national systems of innovation from the South. Industry and Innovation, 7(1), 55-75.

Arocena, R., and Sutz, J. (2000b). Interactive learning spaces and development policies in Latin America. Copenhagen: Department of Industrial Economics and Strategy, Copenhagen Business School.

Asheim, B., and Gertler, M. (2004). The geography of innovation: Regional innovation systems. In J. Fagerberg, D. C. Mowery and R. R. Nelson (eds.), The Oxford handbook of innovation (pp. 291-217). Oxford: Oxford University Press.

Carlsson, B., and Stankiewicz, R. (1991). On the nature, function and composition of technological systems. Journal of Evolutionary Economics, 1(2), 93-118.

Cassiolato, J. E., Lastres, H. M. M., and Maciel, L. (2003). Systems of innovation and development: Evidence from Brazil. Cheltenham, UK and Northampton, MA: Edward Elgar Publishing.

Chaminade, C., and Vang, J. (2008). Globalisation of knowledge production and regional innovation policy: Supporting specialized hubs in the Bangalore software industry. Research Policy, 37(10), 1684-1696.

de Melo, M., Denizer, C., Gelb, A., and Tenev, S. (2001). Circumstance and choice: The role of initial conditions and policies in transition economies. The World Bank Economic Review, 15(1), 1-31.

Dutrénit, G., and Sutz, J. (2014). Sistemas de Innovación para un Desarrollo Inclusivo. La experiencia latinoamericana. Ciudad de México: FCCyT.

Granstrand, O. (2000). The shift towards intellectual capitalism - the role of infocom technologies. Research Policy, 29(9), 1061-1080.

Johnson, B. H., and Andersen, A. D. (2012). Learning, innovation and inclusive development: New perspectives on economic development strategy and development aid (Globelics Thematic Report, Vol. 2011/2012). Aalborg: Aalborg Universitetsforlag.

Lalics (2014). Declaración LALICS: Aportes desde la Ciencia, la Tecnología y la Innovación a la Inclusión Social, accessed 13 November 2016 at http://lalics.org/ index.php?option $=$ com_content $\&$ view $=$ article\&id $=180$ :declaracion-lalics\&cat $\mathrm{id}=2$ : uncategorised $\&$ Itemid $=108 \&$ lang $=e s$.

Lundvall, B.-A. (1992). National systems of innovation: An analytical framework. London: Pinter.

Lundvall, B.-Å., Joseph, K., Chaminade, C., and Vang, J. (2011). Handbook of innovation systems and developing countries: Building domestic capabilities in a global setting. Cheltenham, UK and Northampton, MA: Edward Elgar Publishing.

Malecki, E. (1997). Technology and economic development: The dynamics of local, 
regional, and national change, accessed 13 November 2016 at https://ssrn.com/ abstract $=1496226$.

Malerba, F. (2002). Sectoral systems of innovation and introduction. Research Policy, 31, 247-264.

McCormick, D., and Atieno, R. (2002). Linkages between small and large firms in the Kenyan food processing sector. In M. En van Dijk and H. Sandee (eds.), Innovation and small enterprises in the Third World (pp. 223-248). Cheltenham, UK and Northampton, MA: Edward Elgar Publishing.

Nelson, R. R. (1993). National innovation systems: A comparative analysis. Oxford: Oxford University Press.

North, D. C. (1990). Institutions, institutional change and economic performance. Cambridge: Cambridge University Press.

Nour, S. S. O. M. (2016). Economic systems of innovation in the Arab region. New York: Palgrave Macmillan.

Paunov, C. (2013). Innovation and inclusive development: A discussion of the main policy issues (OECD Science, Technology and Industry Working Papers, No. 2013/01). Paris: OECD.

Pietrobelli, C., and Rabellotti, R. (2011). Global Value Chains meet innovation systems: Are there learning opportunities for developing countries? World Development, 39(7), 1261-1269.

Srholec, M., and Verspagen, B. (2008). The voyage of the Beagle in innovation systems land: Explorations on sectors, innovation, heterogeneity and selection (Working Paper 2008-008). Maastricht: UNU-MERIT.

Uyarra, E. (2010). What is evolutionary about "regional systems of innovation"? Implications for regional policy. Journal of Evolutionary Economics, 20(1), 115-137. 
Jana Schmutzler, Marcela Suarez, Alexandra Tsvetkova, and Alessandra Faggian - 9781785369667 Downloaded from PubFactory at 04/26/2023 10:31:44AM 